\title{
The effects of different V-sit positions on abdominal muscle activation
}

\author{
Jina Seo ${ }^{a}$, Yijung Chung ${ }^{b(1)}$

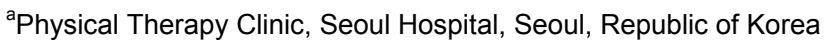 \\ ${ }^{b}$ Department of Physical Therapy, College of Health Science and Social Welfare, Sahmyook University, Seoul, Republic of Korea
}

Objective: This study aimed to identify the effects of performing shoulder and hip abduction during the V-sit exercise on abdominal muscle activity.

Design: Cross-sectional study.

Methods: Thirty healthy adults volunteered for this experiment. The participants randomly performed 6 types of V-sit exercises, including V-sit alone (hip $0^{\circ}$, shoulder $0^{\circ}$ ), V-sit with hip abduction $0^{\circ}$ and shoulder abduction $15^{\circ}, \mathrm{V}$-sit with hip abduction $0^{\circ}$ and shoulder abduction $30^{\circ}$, V-sit with hip abduction $15^{\circ}$ and shoulder abduction $0^{\circ}$, V-sit with shoulder and hip abduction $15^{\circ}$, and V-sit with shoulder abduction $30^{\circ}$ and hip abduction $15^{\circ}$. EMG data were recorded from the rectus abdominis (RA), external oblique (EO), and internal oblique (IO) muscles of both sides. All abdominal EMG data during the six types of V-sit exercises were measured for 5 seconds, three times, and recorded for the middle 3 seconds excluding the 1 second at the start and end.

Results: V-sit with shoulder abduction $30^{\circ}$ resulted in significantly greater muscle activity of both RA, EO compared to shoulder abduction $0^{\circ}$, shoulder abduction $15^{\circ}(p<0.05)$ and $\mathrm{V}$-sit with shoulder abduction $15^{\circ}$ showed significantly greater muscle activation of the RA compared with shoulder abduction $0^{\circ}(p<0.05)$. The muscle activity of both EO and IO in the V-sit with hip abduction $15^{\circ}$ was significantly greater than hip abduction $0^{\circ}$ in all shoulder conditions $(p<0.05)$.

Conclusions: Greater angles of shoulder and hip abduction produced more abdominal muscle activity increases during the V-sit exercises. Shoulder abduction affected the RA, EO muscle activation and hip abduction affected the EO, IO muscle activation. This study showed that shoulder and hip abduction during V-sit exercises enabled effective activation of the trunk muscles.

Key Words: Abdominal muscles, Electromyography, Hip joint, Posture, Shoulder joint

\section{Introduction}

Stability refers to the function of the musculoskeletal system to maintain equilibrium against disturbance of kinematic control [1]. At this time, the stabilization of the trunk is performed through three sub-systems of passive, active, and neural regulation. The active regulation system is composed of the core muscle system, providing dynamic stabilization to the proximal part of the spine and limbs, as well as the neural regulation system, and conveys information about movement [2]. In other words, it can be said that the active muscle power produced by the core muscles play a major role in maintaining trunk stability against the external load imposed on our body [3]. At this time, abdominal strengthening exercises that improve trunk stability have a positive effect on reducing low back pain, improving upper limb function in patients with breast cancer, and contribute to improving lower limb function in patients with hip and total knee arthroplasty, as well as improve capacity and exercise performance in athletes [4].

Therefore, abdominal strengthening exercises are widely practiced not only in physical therapy, but also in sports and

Received: 31 August, 2020 Revised: 22 September, 2020 Accepted: 24 September, 2020

Corresponding author: Yijung Chung (ORCID https://orcid.org/0000-0002-2431-8895)

Department of Physical Therapy, College of Health Science and Social Welfare, Sahmyook University, 815 Hwarang-ro, Nowon-gu, Seoul 01795 , Republic of Korea Tel: 82-2-3399-1637 Fax: 82-2-3399-1639 E-mail: yijung36@syu.ac.kr

(c) This is an Open-Access article distributed under the terms of the Creative Commons Attribution Non-Commercial License (http://creativecommons.org/licenses/ by-nc/4.0) which permits unrestricted non-commercial use, distribution, and reproduction in any medium, provided the original work is properly cited.

Copyright @ 2020 Korean Academy of Physical Therapy Rehabilitation Science 
physical education [5].

In general, abdominal strengthening exercises are commonly used in a supine position, such as sit-ups, and trunk flexion exercises are commonly used [6]. In this case, several studies have suggested that in the case of V-sit exercise, more effective abdominal muscle activation can be expected than the sit-up exercise by simultaneously moving the upper and lower bodies [7]. This can be seen from the results of a study that compared the abdominal muscle activity of the sit-up and V-sit posture where the V-sit posture showed relatively greater muscle activity in the lower rectus abdominis (RA) and external oblique muscles [8]. In addition, the additional limb movements can cause predictable perturbation in our body and promote the activation of abdominal muscles to maintain body stability [9]. Based on the results of a previous study comparing the abdominal muscle activity according to the hip joint movement of the bridge exercise, the abdominal muscle activity of the RA and the internal abdominal oblique muscle was greater when the hip joint was abducted during the bridge exercise than when the hip was not abducted [10]. In addition, in a study comparing abdominal muscle activity when one hip was abducted and not abducted during a straight leg raise, the muscle activity of the ipsilateral external oblique (EO) muscle was greater as a result of abducting the hip joint [11].

Since the abdominal muscles have different directions of movement of the various muscle fibers, it is believed that the response to the load applied in different postures will be different [11]. In a previous study, it was reported that shoulder flexion induces back muscle activation while shoulder abduction induces abdominal muscle activation [12].

This can be seen from the results of a study that measured the abdominal muscle activity according to the movement of the limb in a sitting position in patients with stroke and the muscle activity of the abdominal muscles was greater than that with shoulder flexion during shoulder abduction [13]. In addition, in a study comparing abdominal muscle activity when standing in normal subjects, in the case of the transverse abdominal muscle, there was no difference in muscle activity according to the movement direction of the limb, and although it was activated first in all directions, the IO muscle was activated more preferentially during shoulder abduction than in the sagittal movement such as shoulder flexion and extension [14].

Among the abdominal muscles, the lateral fibers of the abdominal and EO muscles are considered to be the main mobilizers of trunk movement, while the internal and trans- verse abdominal muscles are considered to be the main stabilizing muscles of trunk movement.

At this time, the stabilizing muscles can be further classified into primary and secondary stabilizing muscles. Primary stabilizing muscles include muscles that cannot cause joint movement relatively, such as the transverse abdominal muscles [2]. The secondary stabilizing muscles include the medial fibers of the internal and EO muscles. These muscles also contribute to stabilization, but also act to move the spinal joints.

At this time, the RA, EOs, and IOs are activated differently according to the direction of movement before the limb movement to stabilize the spine, whereas the transverse abdominal muscles act before movement in all directions regardless of the movement direction of the limb and are involved in maintaining posture.

In addition, the IO muscle is attached to the lumbar spine and contributes to spinal stabilization through the control of intervertebral stiffness [15].

Existing studies on the V-sit posture were limited to comparing abdominal muscle activity according to the angle of lifting the leg from the ground [16] and comparing abdominal muscle activity with the most clinically used abdominal strength training exercises [8].

Therefore, studies analyzing the change of abdominal muscle activity according to the change of upper or lower limb posture in V-sit posture are insufficient.

Therefore, this study attempted to present basic data for future exercise regimens by applying postural change to V-sit exercises in healthy subjects and examining the effect of postural change on abdominal muscle activity.

\section{Methods}

\section{Study participants}

This study included 30 subjects who had met the subject selection criteria among healthy adults. Before proceeding with the experiment, after explaining the experiment procedure and conditions to the study subjects, the study participants agreed to volunteer and signed the consent form.

The selection criteria for subjects were those who could maintain a certain posture for more than 30 seconds after lifting the trunk or both lower limbs [17], and the exclusion criteria were those who had experienced low back pain in the last 6 months, had severe scoliosis or congenital spine. Those with deformities, those who were unable to perform exercise due to cancer or pregnancy, spinal disorders such as 
herniated discs [18], a history of neurological disorders and spinal surgery [19], pain in the lower back or abdomen, a wound or injury to the stomach due to surgery or trauma were excluded [8].

\section{Research procedure}

In this study, 30 healthy adults who met the subject selection criteria were selected as the study participants and the investigation was conducted through a cross-sectional study design. Prior to the start of the experiment, the procedure was fully explained to the subjects, and after the subjects fully understood and signed the consent form, the experiment was conducted. The study was approved by the Institutional review board of Sahmyook University (2-7001793-AB-N-012018052HR).

For normalization of muscle activity, electrodes were attached to both RA, external and internal rectus muscles, and then the maximum voluntary isometric contraction (MVIC) was measured [20]. When performing the V-sit posture, muscle activity was repeatedly measured 3 times and the average was obtained for each movement by applying bilateral hip $0^{\circ}$ abduction and $15^{\circ}$ abduction to each condition of bilateral shoulder $0^{\circ}$ abduction, $15^{\circ}$ abduction, and $30^{\circ}$. In order to minimize muscle fatigue in each posture, a 1-minute rest period was provided for each movement [21].

\section{Measurement and evaluation method}

In this study, in the $\mathrm{V}$-sit position, bilateral hip joint $0^{\circ} \mathrm{ab}$ duction, bilateral shoulder joint $0^{\circ}$ abduction, $15^{\circ}$ abduction, and $30^{\circ}$ abduction were performed. Abduction was performed to measure the muscle activity of the target muscles.

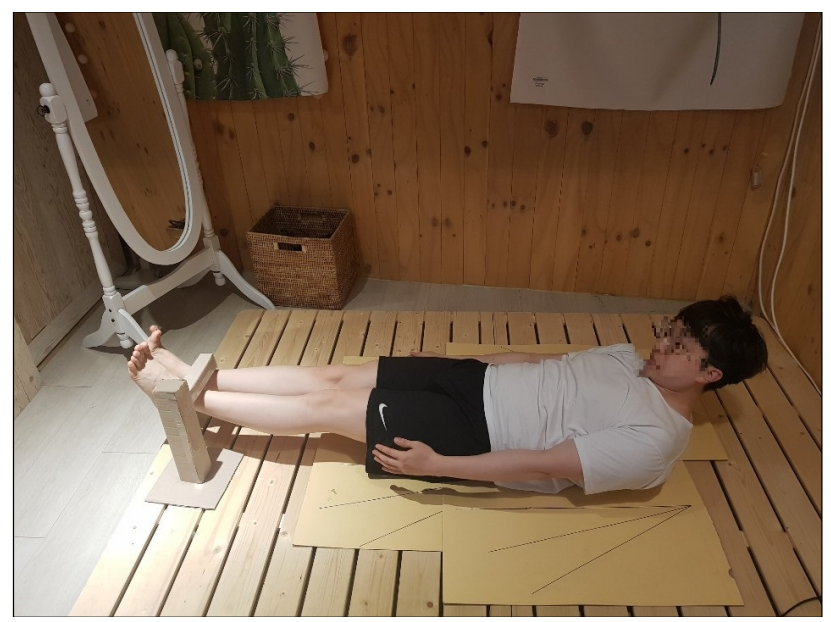

Figure 1. V-sit position.
Before the experiment, the V-sit posture and the upper and lower limb postures were sufficiently explained to the study subject, and the study was conducted after preliminary practice so that the study subject could fully understand the experimental movements.

The starting position for each movement entailed having the subjects placing their to both sides of the trunk in the supine position.

When performing the V-sit posture, subjects flexed their head, shoulders and trunk so that their scapulae did not touch the ground [8] and the cervical spine was flexed as much as possible [22]. At the same time, both lower limbs were lifted until the knee joint was fully extended and the hip joint flexion reached $10^{\circ}$. The hip joint was flexed until it reached the wooden model (Figure 1) [23].

At the time of measurement, subjects were asked to lift their head, shoulders, trunk, and both lower limbs for $1 \mathrm{sec}-$ ond with the bell sound of the experimenter, and after holding this for 3 seconds, they slowly lowered their upper and lower bodies within 1 second to return to the starting position. Shoulder and hip abduction movements were made by applying the guidelines that were prepared on four boards. For the shoulder joint, the axis of the guideline was placed at the center point of the back of the shoulder joint. In the case of the hip joint, after placing the center point under the subject's superior iliac spine a wooden model was set up at the limit of the angle of abduction of each limb, so that the subject could recognize when the abduction movement exceeded the limit [24]. Shoulder and hip abduction movements (Figure 2) were performed simultaneously for $1 \mathrm{sec}-$ ond by lifting the head, shoulders, trunk, and both legs.

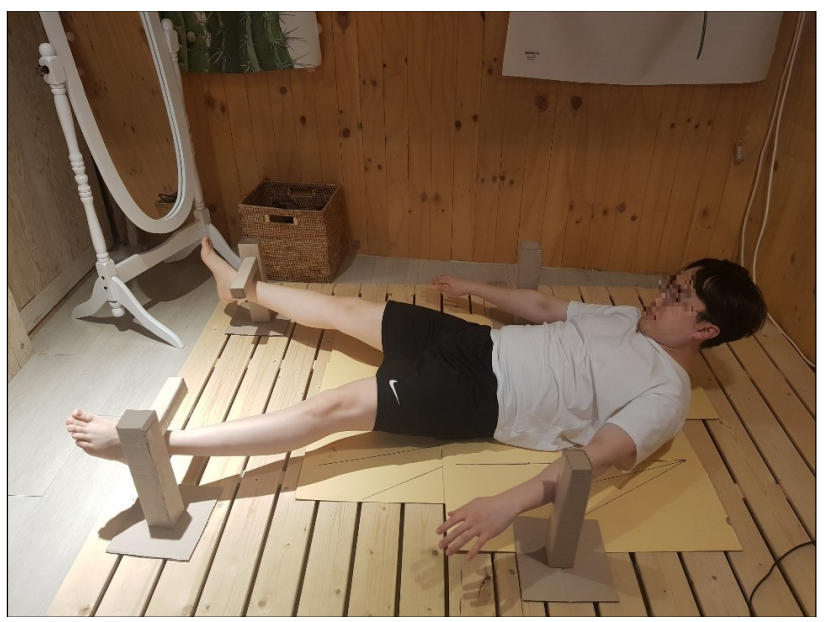

Figure 2. Shoulder abduction, hip abduction of V sit position. 
Similarly, after holding for 3 seconds, both the upper and lower limbs were to return to the starting position within 1 second. During all movements, a metronome was set for 60 times per minute to measure the execution time, and when the inspector found an error in the tree model, the measured value was deleted. Each movement was performed in random order using a random number table and each condition was measured three times. In addition, in order to minimize muscle fatigue of the study subjects, they were given a 1-minute break after each movement [21].

To measure muscle activity in each motion, the surface telemetry EMG system (TELEmyo 2400T G2; Noraxon, Scottsdale, AZ, USA, 2011) was used to measure the muscle activities of bilateral RA, EOs, and the IO muscles (inferior fibers of the IO), and the sampling rate of the EMG signal was set to $1,500 \mathrm{HZ}$, and the frequency bandwidth was set to 20-500 HZ. In this study, the measured muscle EMG signals were processed by full wave rectification using the MyoResearch XP Master edition software (Noraxon, 2011), and then root mean square 250 milliseconds was taken [25]. In the case of the IO muscle, the electrodes were attached in parallel with the muscle fiber in the lower part of the upper anterior iliac spine, and in the case of the EO muscles, the electrodes were attached parallel to the muscle fibers. Also, in the case of the rectus abdominal muscle, the electrodes were attached in parallel with the muscle fibers at a distance of $2 \mathrm{~cm}$ outward from the midline and $3 \mathrm{~cm}$ above the belly button [9]. Skin resistance was minimized by removing body hair before attaching the electrode and cleaning the electrode site with an alcohol cotton [26].

To assess the MVIC of each muscle, electrodes were attached to both internal, EO muscles and the rectus abdominal muscles, and the measurement posture of each muscle was performed based on the manual muscle test for each respective muscle. The rectus abdominal muscle was measured by flexing the knee to $90^{\circ}$ in a supine position, fixing both feet, and applying resistance to the shoulder in the direction of trunk extension when the trunk was maximally flexed. The IO and EO muscles were measured by applying resistance to the shoulder in the opposite direction of rotation while the trunk was maximally flexed in the same posture as the abdominal rectus muscle and the trunk was rotated left and right [20].

As for the normalization method, the EMG signal extracted from the center of the 3 second section in the static state was divided by the MVIC value and normalized to the $\%$ MVIC value with the exclusion of the 1 second time peri- od before and after the movement occurred during each 5 second exercise [9].

\section{Statistical analysis}

For all work and statistics in this study, the mean and standard deviation values were calculated using the IBM SPSS Statistics for Windows, Version 19.0 (IBM Co., Armonk, NY, USA), and descriptive statistics were used for the general characteristics of the subjects.

To investigate the effect of $\mathrm{V}$-sit posture on abdominal muscle activity, there were 3 upper extremity postural conditions of shoulder joint $0^{\circ}$ abduction, $15^{\circ}$ abduction, and $30^{\circ}$ abduction, and the hip joint $0^{\circ}$ abduction and $15^{\circ}$ abduction. A two-way repeated measure ANOVA was performed for a total of six movements with the conditions applied. Post-hoc verification was performed using the least significant difference, and the statistical significance level (p) of all data was set to 0.05 .

\section{Results}

The muscle activity of the bilateral RA was significantly affected by the change of all upper limb postures $(\mathrm{F}=8.427$, $p<0.001 ; \mathrm{F}=9.459, p<0.001)$, but the main effect of the change of lower limb posture and the interaction effect of the change of upper and lower limb posture were not significant.

As a result of post-hoc analysis, the muscle activity of the bilateral RA was significantly greater in all hip abduction conditions in the shoulder $30^{\circ}$ abduction condition, and it was significantly greater than in the shoulder joint $0^{\circ}$ and $15^{\circ}$ abduction conditions $(p<0.05)$.

The muscle activity of both EO muscles was significantly affected by the changes in all upper extremity postures $(\mathrm{F}=4.900, p=0.009 ; \mathrm{F}=4.137, p=0.018)$ and the main effects according to lower limb posture changes $(\mathrm{F}=19.921$, $p<0.001 ; \mathrm{F}=10.270, p=0.002$ ) The interaction effect according to the posture of upper and lower limbs was not significant. As a result of post-hoc analysis, the muscle activity of both EO muscles was significantly greater in the $15^{\circ}$ hip abduction condition and the $30^{\circ}$ shoulder abduction condition than in the shoulder joint $0^{\circ}$ abduction $(p<0.05)$, and in all hip abduction conditions, muscle activity was significantly greater in the shoulder $30^{\circ}$ abduction condition than in the $15^{\circ}$ abduction of the shoulder joint $(p<0.05)$.

In addition, in all shoulder abduction conditions, muscle activity was significantly greater in hip $15^{\circ}$ abduction than $0^{\circ}$ abduction $(p<0.05)$. The effects of all lower limb posture 
Table 1. Muscle activation of abdominal muscles

$(\mathrm{N}=30)$

\begin{tabular}{|c|c|c|c|c|c|c|}
\hline & \multicolumn{3}{|c|}{ Muscle activation } & \multirow{2}{*}{$\begin{array}{c}\begin{array}{c}\text { Main effect } \\
\text { (upper) }\end{array} \\
\mathrm{F}(p)\end{array}$} & \multirow{2}{*}{$\begin{array}{c}\begin{array}{c}\text { Main effect } \\
\text { (lower) }\end{array} \\
\mathrm{F}(p)\end{array}$} & \multirow{2}{*}{$\begin{array}{c}\begin{array}{c}\text { Interaction } \\
\text { (upper*lower) }\end{array} \\
\mathrm{F}(p)\end{array}$} \\
\hline & S0 & S15 & $\mathrm{S} 30$ & & & \\
\hline Rt.RA (\%MVIC) & & & & $8.427(<0.001)$ & $2.394(0.124)$ & $0.369(0.692)$ \\
\hline H0 & $61.84(11.45)$ & $65.30(12.13)^{\mathrm{a}}$ & $71.40(11.20)^{\mathrm{ab}}$ & & & \\
\hline $\mathrm{H} 15$ & $64.48(12.38)$ & $68.70(12.17)^{\mathrm{a}}$ & $72.18(11.92)^{\mathrm{ab}}$ & & & \\
\hline Lt.RA (\%MVIC) & & & & $9.459(<0.001)$ & $2.479(0.117)$ & $0.167(0.846)$ \\
\hline $\mathrm{H} 0$ & $56.46(12.54)$ & $62.44(13.39)^{\mathrm{a}}$ & $68.53(14.28)^{\mathrm{ab}}$ & & & \\
\hline H15 & $60.78(11.65)$ & $66.03(13.44)^{\mathrm{a}}$ & $70.10(14.01)^{\mathrm{ab}}$ & & & \\
\hline Rt.EO (\%MVIC) & & & & $4.900(0.009)$ & $19.921(<0.001)$ & $2.137(0.121)$ \\
\hline Ho & $60.29(12.38)$ & $60.23(10.07)$ & $62.23(11.01)^{\mathrm{ab}}$ & & & \\
\hline $\mathrm{H} 15$ & $64.61(11.37)^{\mathrm{c}}$ & $66.33(11.97)^{c}$ & $74.81(10.94)^{\mathrm{abc}}$ & & & \\
\hline Lt.EO (\%MVIC) & & & & $4.137(0.018)$ & $10.270(0.002)$ & $1.247(0.290)$ \\
\hline $\mathrm{HO}$ & $55.89(17.62)$ & $56.32(19.05)$ & $59.71(17.14)^{\mathrm{ab}}$ & & & \\
\hline $\mathrm{H} 15$ & $60.23(16.84)^{\mathrm{c}}$ & $63.09(17.13)^{\mathrm{c}}$ & $72.93(15.18)^{\mathrm{abc}}$ & & & \\
\hline Rt.IO (\%MVIC) & & & & $2.308(0.103)$ & $35.645(<0.001)$ & $0.069(0.933)$ \\
\hline $\mathrm{H} 0$ & $49.19(9.11)$ & $50.26(8.20)$ & $52.62(9.95)$ & & & \\
\hline $\mathrm{H} 15$ & $57.69(9.78)^{\mathrm{c}}$ & $59.89(11.73)^{\mathrm{c}}$ & $62.42(12.33)^{\mathrm{c}}$ & & & \\
\hline Lt.IO (\%MVIC) & & & & $0.832(0.437)$ & $19.956(<0.001)$ & $0.143(0.867)$ \\
\hline $\mathrm{H} 0$ & $52.79(12.92)$ & $54.55(12.30)$ & $55.04(11.88)$ & & & \\
\hline H15 & $61.68(16.53)^{\mathrm{c}}$ & $63.08(14.33)^{\mathrm{c}}$ & $66.14(15.60)^{\mathrm{c}}$ & & & \\
\hline
\end{tabular}

Values are presented as mean (SD).

\%MVIC: \%maximum voluntary isometric contraction, Rt: right, Lt: left, S0: shoulder abduction $0^{\circ}, \mathrm{S} 15$ : shoulder abduction $15^{\circ}, \mathrm{S} 30$ : shoulder abduction $30^{\circ}, \mathrm{H} 0$ : hip abduction $0^{\circ}$, H15: hip abduction $15^{\circ}$.

RA: rectus abdominis, EO: external oblique, IO: internal oblique.

${ }^{\mathrm{a}}$ Significant difference with S0 $(p<0.05)$, ${ }^{\mathrm{b}}$ Significant difference with S15 $(p<0.05)$, ${ }^{\mathrm{C}}$ Significant difference with H0 $(p<0.05)$.

changes were significant $(\mathrm{F}=35.645, p<0.001 ; \mathrm{F}=19.956$, $p<0.001$ ) on the muscle activity of the bilateral IO muscles, but the effect according to the changes in upper limb posture and the interaction effect the changes in upper and lower limb postures were not significant. As a result of post-hoc analysis, the muscle activity of both IO muscles in all shoulder abduction conditions was significantly greater in the hip $15^{\circ}$ abduction than in the $0^{\circ}$ abduction $(p<0.05$; Table 1).

\section{Discussion}

Son et al. [16] compared abdominal muscle activity according to the hip joint flexion angle in the $\mathrm{V}$-sit posture and found that the abdominal muscle activity was the highest between $5^{\circ}$ and $24^{\circ}$. Therefore, the V-sit posture in this study was performed by setting the hip flexion angle to $10^{\circ}$. At this time, Hong et al. [27] measured the distance of the subacromial space according to the shoulder abduction angle in healthy subjects. When the shoulder joint was abducted to $30^{\circ}$, the average of the subacromial space distance was 9.40 $\mathrm{mm}$, but when shoulder joint was abducted by $60^{\circ}$, the average was $8.01 \mathrm{~mm}$, which was less than that of patients with rotator cuff disease.

Therefore, this study compared abdominal muscle activity according to the changes in upper limb posture during the $\mathrm{V}$-sit posture by setting the shoulder abduction angles to $15^{\circ}$ and $30^{\circ}$ within $60^{\circ}$.

Park et al. [10] compared abdominal muscle activity for basic bridge exercises and lower limb postural changes by abducting the hip joint by $20^{\circ}$ during the bridge exercise. Abdominal muscle activity due the postural change was compared. Park [11] compared the abdominal muscle activity against changes in lower extremity posture by abducting the hip joint by $15^{\circ}$ and $30^{\circ}$ when lifting the leg.

Rutkowska and Szpala [5] argued that the change in upper limb posture changes the center of mass of the trunk, and this change in the center of mass of the trunk changes the moment from the axis of rotation of the upper body to the center of mass, thereby changing the load that the abdominal muscles must cope with for trunk stabilization. That is, as the load due to the increase of the moment arm gradually in- 
creased, the muscle activity of the abdominal muscles for posture maintenance increased [6]. Therefore, as the shoulder abduction angle, which is a change in the upper limb posture, increases, the center of mass moves toward the head (cranial position), and the load that the abdominal muscles have to resist when the trunk flexion is increased. However, according to Crommert et al. [6], the transverse abdominal muscle, the innermost muscle among the abdominal muscles, does not directly act on trunk flexion due to a lack of bone attachment points, but acts as an aid. Therefore, it is considered that the transverse abdominal muscle was not affected by the external load due to the changes in upper limb posture compared to other muscles.

Park et al. [10] compared the muscle activity of the RA muscle and the internal abdominal oblique muscle during hip joint abduction during bridge exercises in healthy subjects. The ratio of the internal abdominal and rectus abdominal muscles was also significantly greater during the abduction of one and both hip joints than the basic bridge exercise $(p<0.05)$.

Park [11] compared the muscle activity of the abdominal rectus, EO, and IO muscles according to hip abduction positions in the supine position in healthy adults. Muscle activity was significantly greater $30^{\circ}$ abduction than that of $0^{\circ}$ abduction $(p<0.05)$.

Kim et al. [15] compared abdominal muscle activity according to hip adduction during plank exercise in normal subjects. The abdominal rectus, EO, and IO muscles all showed significantly greater muscle activity with hip adduction than the basic plank exercise with hip adduction on one side. Except for the rectus abdominis, the case of the external and IO muscle activity was significantly greater with single hip adduction compared to bilateral hip adduction $(p<0.05)$.

In this study, according to the changes in lower limb posture in the $\mathrm{V}$-sit posture, there was a significant difference in muscle activity between the external and IO muscles, but not in the case of bilateral RA. At this time, both external and IO muscles showed significantly greater muscle activity in the $15^{\circ}$ hip abduction condition than the $0^{\circ}$ hip abduction $(p<0.05)$.

Since abdominal muscles do not pass through the hip joint, they are not directly involved in hip joint flexion [28], but in supine position, hip joint flexion acts as an external resistance that breaks the static stability of the body by the weight of the leg [11]. Also, at this time, the change in the position of the lower limbs creates a load by the change of the moment arm by changing the center of mass of the body by the weight of the leg, which also occurs with the change in the position of the upper limbs [5].

In addition, according to Park [11], hip abduction acts as a force that causes the opposite pelvis and trunk to rotate ipsilaterally, and in the case of the external and IO muscles, which are involved in rotating the trunk, they work together to produce counter rotation due to the weight of the leg.

In terms of functional anatomy, abdominal muscles are divided into global muscles and local muscles. The large muscles include the RA and the EO muscles, and the local muscles include the transverse abdominal muscles and the IO muscles [19].

At this time, Moon and Goo [29] suggested that the transverse abdominal muscle contraction occurs more effectively with positional changes of the lower extremity than the upper extremity, because the lumbar spine and the thighs are in the same nerve dominant area.

In other words, the hip abduction muscles are connected through the local muscles of the abdomen and the superior anterior iliac spine of the pelvis, so the hip abduction contributes to the transfer of force to the local muscles of the abdomen [30]. As a result, it is thought that the contraction of the lower extremity complex affected the activation of trunk stabilizing muscles such as the transverse abdominis and the IO muscles [31,32].

The limitation of this study is that the size of the sample group is small, and since the experiment was conducted on healthy adults, it is difficult to generalize to groups with specific characteristics such as low back pain and patients with stroke.

Therefore, in future studies, in-depth studies will be needed for groups with characteristics of specific diseases.

Therefore, although the V-sit posture differed in the types of abdominal muscles that were effective according to changes in the upper and lower limb posture, it is thought that changes in upper and lower extremity postures such as shoulder abduction and hip abduction in the V-sit posture can induce muscle activity of the abdominal muscles more effectively by increasing the load on the muscles that the abdominal muscles must counter.

\section{Acknowledgements}

This paper was supported by the Korean Academy of Women's Health in Physical Therapy and the Institute of Women's Health in Physical Therapy of Sahmyook 
University.

\section{Conflict of Interest}

The authors declared no potential conflicts of interest with respect to the authorship and/or publication of this article.

\section{References}

1. Granata KP, Lee PE, Franklin TC. Co-contraction recruitment and spinal load during isometric trunk flexion and extension. Clin Biomech (Bristol, Avon) 2005;20:1029-37.

2. Huxel Bliven KC, Anderson BE. Core stability training for injury prevention. Sports Health 2013;5:514-22.

3. Hubley-Kozey CL, Vezina MJ. Muscle activation during exercises to improve trunk stability in men with low back pain. Arch Phys Med Rehabil 2002;83:1100-8.

4. Keays KS, Harris SR, Lucyshyn JM, MacIntyre DL. Effects of Pilates exercises on shoulder range of motion, pain, mood, and upper-extremity function in women living with breast cancer: a pilot study. Phys Ther 2008;88:494-510.

5. Rutkowska-Kucharska A, Szpala A. Electromyographic muscle activity in curl-up exercises with different positions of upper and lower extremities. J Strength Cond Res 2010;24:3133-9.

6. Crommert ME, Bjerkefors A, Tarassova O, Ekblom MM. Abdominal muscle activation during common modifications of the trunk curl-up exercise. J Strength Cond Res 2018. doi: 10.1519/JSC.0000000000002439 [Epub ahead of print]

7. Monfort-Pañego M, Vera-García FJ, Sánchez-Zuriaga D, Sarti-Martínez MA. Electromyographic studies in abdominal exercises: a literature synthesis. J Manipulative Physiol Ther 2009; 32:232-44

8. Willett GM, Hyde JE, Uhrlaub MB, Wendel CL, Karst GM. Relative activity of abdominal muscles during commonly prescribed strengthening exercises. J Strength Cond Res 2001;15: 480-5.

9. Marshall P, Murphy B. The validity and reliability of surface EMG to assess the neuromuscular response of the abdominal muscles to rapid limb movement. J Electromyogr Kinesiol 2003; 13:477-89.

10. Park HJ, Oh DW, Kim SY. Effects of integrating hip movements into bridge exercises on electromyographic activities of selected trunk muscles in healthy individuals. Man Ther 2014;19:246-51.

11. Park MC. The effects of hip abduction angles on abdominal muscle activity during leg raising. J Korean Soc Phys Med 2012;7: 165-71.

12. Mullington CJ, Klungarvuth L, Catley M, McGregor AH, Strutton PH. Trunk muscle responses following unpredictable loading of an abducted arm. Gait Posture 2009;30:181-6.

13. Lee DK, Kang MH, Kim JW, Kim YG, Park JH, Oh JS. Effects of non-paretic arm exercises using a tubing band on abdominal muscle activity in stroke patients. NeuroRehabilitation 2013;33: 605-10.

14. Hodges PW, Richardson CA. Inefficient muscular stabilization of the lumbar spine associated with low back pain. A motor control evaluation of transversus abdominis. Spine 1996;21:2640-50.

15. Kim SY, Kang MH, Kim ER, Jung IG, Seo EY, Oh JS. Comparison of EMG activity on abdominal muscles during plank exercise with unilateral and bilateral additional isometric hip adduction. J Electromyogr Kinesiol 2016;30:9-14.

16. Son NJ, Jun HJ, Yi KO. Angular differences between the lower extremity and the ground that express maximum core muscle activation according to core-strengthening exercises. Korean J Sport Biomech 2017;27:247-55.

17. Kim HD, Jeon DM, Bae HW, Kim JG, Han N, Eom MJ. Changes in activation of abdominal muscles at selected angles during trunk exercise by using ultrasonography. Ann Rehabil Med 2015;39:950-6.

18. Dias JM, Menacho Mde O, Mazuquin BF, Obara K, Mostagi FQ, Lima TB, et al. Comparison of the electromyographic activity of the anterior trunk during the execution of two Pilates exercises teaser and longspine - for healthy people. J Electromyogr Kinesiol 2014;24:689-97.

19. Imai A, Kaneoka K, Okubo Y, Shiina I, Tatsumura M, Izumi S, Shiraki H. Trunk muscle activity during lumbar stabilization exercises on both a stable and unstable surface. J Orthop Sports Phys Ther 2010;40:369-75.

20. Kendall FP, McCreary EK, Provance PG, Rodgers MM, Romani WA. Muscles: testing and function with posture and pain. 5 th ed. Baltimore (MD): Lippincott Williams \& Wilkins; 2005.

21. D'hooge R, Hodges P, Tsao H, Hall L, Macdonald D, Danneels L. Altered trunk muscle coordination during rapid trunk flexion in people in remission of recurrent low back pain. J Electromyogr Kinesiol 2013;23:173-81.

22. Shirado O, Ito T, Kaneda K, Strax TE. Electromyographic analysis of four techniques for isometric trunk muscle exercises. Arch Phys Med Rehabil 1995;76:225-9.

23. Choi SA, Cynn HS, Yi CH, Kwon OY, Yoon TL, Choi WJ, et al. Isometric hip abduction using a Thera-Band alters gluteus maximus muscle activity and the anterior pelvic tilt angle during bridging exercise. J Electromyogr Kinesiol 2015;25:310-5.

24. Kang SY, Jeon HS, Kwon O, Cynn HS, Choi B. Activation of the gluteus maximus and hamstring muscles during prone hip extension with knee flexion in three hip abduction positions. Man Ther 2013;18:303-7.

25. Suehiro T, Mizutani M, Watanabe S, Ishida H, Kobara K, Osaka $\mathrm{H}$. Comparison of spine motion and trunk muscle activity between abdominal hollowing and abdominal bracing maneuvers during prone hip extension. J Bodyw Mov Ther 2014;18:482-8.

26. Criswell E, Cram JR. Cram's introduction to surface electromyography. 2nd ed. Sudbury (MA): Jones and Bartlett Publishers; 2011.

27. Hong YT, Lee DY, Yu JH, Kim JS, Hong JH. Changes in the subacromial space according to the angle of shoulder abduction. Indian J Sci Technol 2015;8:1-6.

28. Andersson EA, Nilsson J, Ma Z, Thorstensson A. Abdominal and hip flexor muscle activation during various training exercises. Eur J Appl Physiol Occup Physiol 1997;75:115-23.

29. Moon HJ, Goo BO. The effect of change in transversus abdominis thickness using ultrasound image during a hip adductor contraction. J Korean Soc Phys Med 2011;6:287-92.

30. Myers TW. Anatomy trains: myofascial meridians for manual and movement therapists. Edinburgh: Churchill Livingstone; 
2001.

31. Page P, Frank CC, Lardner R. Assessment and treatment of muscle imbalance: the Janda approach. Champaign (IL): Human Kinetics; 2010.
32. Tarnanen SP, Ylinen JJ, Siekkinen KM, Mälkiä EA, Kautiainen HJ, Häkkinen AH. Effect of isometric upper-extremity exercises on the activation of core stabilizing muscles. Arch Phys Med Rehabil 2008;89:513-21. 